\title{
Depression before and after cardiac surgery: Do all patients respond the same?
}

\author{
David Horne, MD, DCH, ${ }^{\text {a }}$ Scott Kehler, BPE, BKin, ${ }^{\mathrm{b}}$ George Kaoukis, PhD, CPsych, ${ }^{\mathrm{c}}$ Brett Hiebert, MSc, ${ }^{\mathrm{a}}$ \\ Eric Garcia, BKin, ${ }^{\mathrm{b}}$ Todd A. Duhamel, PhD, MSc, ${ }^{\mathrm{b}}$ and Rakesh C. Arora, MD, PhD, FRCSC, FACS ${ }^{\mathrm{a}}$
}

Objective: To characterize the prevalence, incidence, and risk factors for depression before and after cardiac surgery.

\begin{abstract}
Methods: Patients awaiting nonemergent surgery $(\mathrm{N}=436)$, completed the Patient Health Questionnaire-9 for depression, as well as the International Physical Activity Questionnaire short version preoperatively (Q1, $\mathrm{n}=436)$ and at hospital discharge $(\mathrm{Q} 2, \mathrm{n}=374)$. At baseline patients were categorized depression "naïve," "at risk," or "depressed." At each interval patients were identified as "not depressed" (Patient Health Questionnaire-9 score 0-3), "possibly depressed" (score 4-9), or "depressed" (score >9). Multivariate logistic regression analysis identified independent baseline and perioperative variables associated with depression.
\end{abstract}

Results: Depression prevalence at Q1 and Q2 was $23.6 \%$ and $37.7 \%$, respectively $(P<.001)$. The incidence of new depression at discharge was $29.2 \%$. Multivariate logistic regression identified independent variables associated with depression: preoperative left ventricular ejection fraction $30 \%$ to $49 \%$ (Q1: odds ratio [OR], 1.81 ; 95\% confidence interval [CI], 1.02-3.21; $P=.042$ ), left ventricular ejection fraction $<30 \%$ (Q1: OR, 2.81; 95\% CI, 1.13-6.96; $P=.026$ ), physical inactivity (Q1: OR, 2.03; 95\% CI; 1.26-3.28; $P=.002$ ), baseline atrisk group $(\mathrm{Q} 2$ : OR, 2.16; 95\% CI, 1.28-3.67; $P=.004)$, baseline depressed group (Q2: OR, 7.46; 95\% CI, 4.06-13.69; $P<.0001)$, hospital length of stay $>7$ days (Q2: OR, 1.62; 95\% CI, 1.03-2.55; $P=.039)$.

Conclusions: Depression is prevalent in one-third of cardiac surgery patients at time of discharge. It is not associated with operative or postoperative risk factors, with the exception of prolonged hospital stay $>7$ days. Preoperative depression or being at risk for depression, is associated with the highest risk for postoperative depression. (J Thorac Cardiovasc Surg 2013;145:1400-6)

Depression after coronary artery bypass grafting (CABG) has been shown to be an independent risk factor for subsequent cardiac events ${ }^{1-3}$ associated with increased risk of hospital re-admission ${ }^{4}$ and in patients with moderate to severe depression is associated with increased risk of death. ${ }^{3,5}$ Despite these assertions, there remains varied reporting on the prevalence of depression after cardiac surgery ranging from $15 \%$ to $47 \% .^{1,3,6}$ Recent publications have indicated that routine screening of depression should be introduced as standard practice in the preoperative assessment of patients undergoing cardiac procedures. ${ }^{3,7}$ McKann and colleagues ${ }^{6}$ reported the incidence of new onset depression to be $13 \%$. The investigators of the Impact of

\footnotetext{
From the Department of Surgery (Cardiac Surgery), ${ }^{\mathrm{a}}$ University of Manitoba; Faculty of Kinesiology and Recreation Management, ${ }^{b}$ and Cardiac Psychology Service, ${ }^{c}$ St. Boniface General Hospital, Winnipeg, Manitoba, Canada.

Disclosures: Authors have nothing to disclose with regard to commercial support.

D.H. and S.K. contributed equally as first authors; T.A.D. and R.C.A. contributed equally as final authors.

Received for publication Aug 7, 2012; revisions received Oct 17, 2012; accepted for publication Nov 6, 2012; available ahead of print Dec 20, 2012.

Address for reprints: David Horne, MD, DCH, Cardiac Surgery Program, St Boniface General Hospital, 3500-9, 409 Tache Ave, Winnipeg, MB, R2H 2A6 Canada (E-mail: drhorne@shaw.ca).

$0022-5223 / \$ 36.00$

Copyright $(C) 2013$ by The American Association for Thoracic Surgery http://dx.doi.org/10.1016/j.jtcvs.2012.11.011
}

Physical Activity on Depression after Cardiac Surgery study sought to characterize depression in a large prospective cohort of patients undergoing cardiac surgery. Our objective was to delineate if different subsets of patients have a different response in mood after cardiac surgery. This was accomplished by determining (1) the prevalence of depression before and after cardiac surgery, (2) the incidence of new depression under patients at risk for depression, and (3) the risk factors associated with depression perioperatively, with an emphasis on self-reported physical activity.

\section{METHODS}

A prospective, observational study was undertaken of 436 consecutively enrolled patients undergoing elective or urgent (waiting in hospital for cardiac surgery) cardiac surgery requiring cardiopulmonary bypass (includes CABG, valve, and other cardiac surgical procedures) from May 2010 through August 2011 (Figure 1). Patients were subsequently followed for a 6-month period postoperatively to identify short-term depression and physical activity behavior. Inclusion criteria for enrolment were any patients older than age 18 years who could read, write, and understand English. Patients with cognitive impairment, or in-hospital stay of $>3$ months were excluded. The study was approved by the University of Manitoba Research Ethics Board, as well as the St. Boniface General Hospital Research Review Board. Written and informed consent was obtained from all patients before enrolment.

Patient baseline characteristics, cardiac risk factors, comorbidities, and previous history of depression, collected as part of our prospective analysis, 


\section{Abbreviations and Acronyms \\ $\mathrm{CABG}=$ coronary artery bypass grafting \\ IPAQ = International Physical Activity \\ Questionnaire \\ LVEF $=$ left ventricular ejection fraction \\ PHQ-9 = Patient Health Questionnaire-9}

are summarized in Table 1. Operative parameters and postoperative data are summarized in Table 2.

The Patient Health Questionnaire-9 (PHQ-9) ${ }^{8}$ was used to assess depressive symptoms at each time point described below. The PHQ-9 consists of 9 items pertaining to the key symptoms of major depressive disorder according to the Diagnostic and Statistical Manual of Mental Disorders, Fourth Edition ${ }^{9}$ and investigates the frequency patients experience these symptoms over a 2 -week period (not at all $=0$, several days $=1$, more than half the days $=2$, or nearly every day $=3$ ). Table 3 explains how patients were classified at baseline. At each interval patients were labeled as depressed (including severity) or not depressed (no depression or possible depression) according to Table 3. An increase in antidepressant dose or initiation of antidepressants was considered deterioration in mood, and subsequently the patient would be reclassified as depressed at that time point if their PHQ-9 score was $<10$. Their PHQ-9 score would also be adjusted to 10 .

Assessment for depression and physical activity was performed preoperatively (Q1), whereas depression only was evaluated on day of discharge from the hospital after cardiac surgery (Q2). Operative and postoperative data were collected after Q2 (Table 2). Further follow-up (with the same assessment tools) in the Impact of Physical Activity on Depression after Cardiac Surgery study was done at 3 months (Q3) and 6 months (Q4) (data not reported).

Physical activity behavior, assessed with the short form International Physical Activity Questionnaire (IPAQ), ${ }^{10}$ utilizes a patient's recall of the amount of physical activity performed during the preceding week to determine the relationship with depression at baseline (Q1) and at discharge (Q2). Activity was reported in terms of minutes per week of vigorous, moderate, walking, sedentary, and total physical activity. Patients were categorized as being inactive, moderately active, or physically active in accordance with the official IPAQ scoring protocol (www.ipaq.ki.se). We combined moderately and physically active into 1 active category. See Table 4 for physical activity scoring classification of IPAQ scores.

\section{Statistical Analysis}

No formal power analysis was conducted. In view of published literature we expected a $20 \%$ to $40 \%{ }^{3,11}$ prevalence of depression before and after cardiac surgery. The expected number of outcomes from a sample size of 400 to 500 would thus exceed 10 times the number of predictors in a multivariable logistic regression model. Once we categorized $>100$ depressed patients at baseline, we believed that the sample size was large enough to allow for high statistical power. Logistic regression modeling was utilized to determine the characteristics of individuals with depression before and after cardiac surgery. Dependent variables for baseline depression were explored by performing univariate logistic regression models for various preoperative characteristics. Operative and postoperative characteristics, along with a preoperative classification of an individual's depression risk group were considered among variables associated with depression at hospital discharge. Stepwise logistic regression was utilized to develop multivariate logistic regression models for independent variables associated with depression at baseline and discharge. Variables with a $P$ value $<.2$ in the univariate analysis were considered among the potential variables for the stepwise logistic regression. Variables for developing new depression at discharge were identified by performing similar univariate and multivariate logistic regression models for patients classified as naïve or at risk at baseline. Univariate and multivariate logistic regression models were also performed for those classified as depressed at baseline to characterize patients who no longer had depression at discharge.

\section{RESULTS}

Prevalence of any depression increased from $23.9 \%$ (104 of 436) preoperatively to $37.7 \%$ (141 of 374 ) postoperatively $(P<.001)$. Table 1 summarizes baseline variables collected and indicates significant preoperative univariate parameters for preoperative depression. Table 2 summarizes operative and postoperative parameters collected at discharge, as well as the significant preoperative univariate parameters associated with depression at discharge. There were no significant differences between depressed or nondepressed patients for operative or postoperative parameters by univariate analyses. Significant independent variables associated with depression at baseline as well as discharge, are summarized in Table 5 (multivariate analysis results).

The increase in prevalence at discharge was due to a $29.2 \%$ (84 of 288) incidence of new depression under patients previously classified as naïve or at risk for depression. There was a $24 \%$ incidence for mild depression, $4.2 \%$ for moderate depression, and only $1 \%$ had severe depression. Significant univariate variables for new depression (same variables as collected in Table 1) were New York Heart Association functional class III or IV $(P=.007$; odds ratio [OR], 2.24; 95\% confidence interval [CI] 1.24-4.05), being at risk for depression preoperatively $(P=.007$; OR, 2.04; $95 \%$ CI, 1.21-3.44), and hospital length of stay $>7$ days $(P=.011$; OR, 1.97; 95\% CI, 1.16-3.34). The same variables were significant in the multivariate logistic model (Table 5).

In contrast, $33.7 \%$ of patients ( 29 of 86 ) classified as depressed before cardiac surgery were not depressed at the time of discharge from hospital. These patients had significantly lower Canadian Cardiovascular Society angina scores preoperatively $(P=.007)$ and fewer had isolated CABG $(P=.02)$ by univariate analyses. There were also more patients with preoperative ejection fraction (LVEF) $<30 \%$ under patients who remained depressed (Table 5). There were no significant differences in change of LVEF from pre- to postoperatively between patients who remained depressed and those whose depressive symptoms improved.

Median PHQ-9 score decreased under preoperative depressed patients (Figure 2) due to $33 \%$ of these patients whose mean scores improved from 10.1 to 4.1. Both naïve and at-risk sub-groups had an increase in median PHQ-9scores (Figure 2) due to new onset depression in both subgroups. For patients with new onset depression, median PHQ-9 score increased from 3.03 to 10.48 (Figure 3), whereas patients who remained not depressed had no 


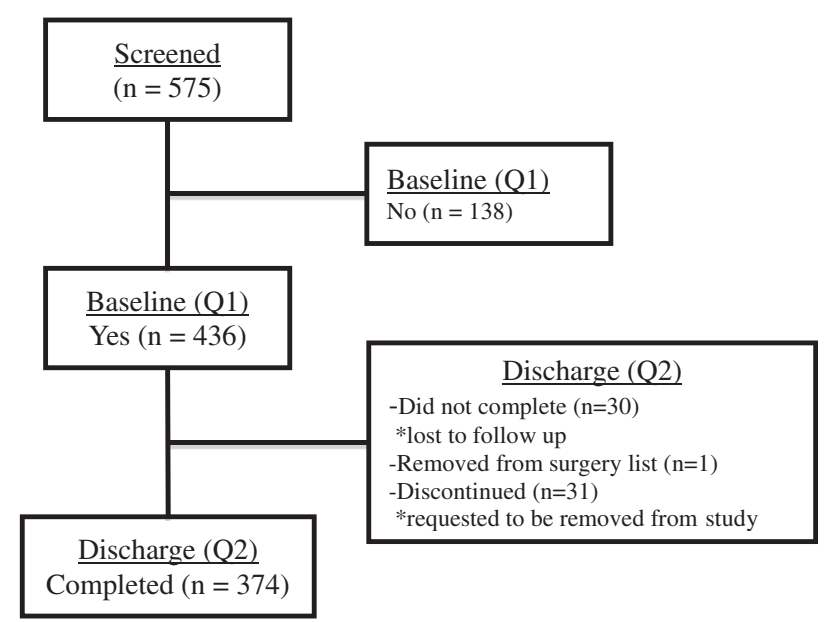

FIGURE 1. Study population flow diagram.

significant change in PHQ-9 score (Figures 3 and 4). Median PHQ-9 scores were similar between patients who remained depressed compared with those with new depression (11.6 vs 10.5 , respectively; $P=.31$ ).

Patients reported accumulating a median 300 (interquartile ratio, 70-840) total minutes of physical activity/week at Q1 (not depressed 325 minutes [range, 105-870 minutes] vs depressed group 200 minutes [range, 20-598 minutes]; $P=.02$ ). Self-reported physical inactivity was significantly associated with depression at baseline by both univariate (OR, 2.11; 95\% CI, 1.35-3.31; $P=.001$ ) as well as multivariate $(\mathrm{OR}, 2.05 ; 95 \% \mathrm{CI}, 1.30-3.23 ; P=.002)$ analysis.

\section{DISCUSSION}

The investigators of the Impact of Physical Activity on Depression after Cardiac Surgery study report data describing depression before and after cardiac surgery in a large, prospective cohort of patients. Analysis of pre- and postoperative data indicate an increase in depression prevalence after cardiac surgery is unrelated to any particular operative parameters and importantly is not restricted to patients undergoing an isolated CABG procedure. Physical inactivity and preoperative LVEF $<50 \%$ independently increased the risk of being depressed preoperatively by 2.0 -fold and 2.8 -fold, respectively. The strongest independent parameters associated with postoperative depression were being depressed or at risk for depression preoperatively. Hospital length of stay $>7$ days was the only independent postoperative variable associated with increased rates of depression at time of discharge. Other independent variables for new onset depression at discharge were preoperative New York Heart Association functional class III or IV (consistent with previous publications ${ }^{12}$ ), being at risk for depression and hospital length of stay $>7$ days.

Length of hospital stay being significantly associated with depression at discharge reflects how medical complications following surgery can be an additional stressor
TABLE 1. Baseline characteristics comparing patients in the depressed subgroup to patients who were not depressed (depression naïve + at risk subgroup) preoperatively

\begin{tabular}{|c|c|c|c|c|c|}
\hline \multirow[b]{2}{*}{ Preoperative } & \multicolumn{2}{|c|}{$\begin{array}{c}\text { Depressed } \\
(\mathrm{n}=104) \\
\end{array}$} & \multicolumn{2}{|c|}{$\begin{array}{c}\text { Not depressed } \\
(\mathbf{n}=\mathbf{3 3 2}) \\
\end{array}$} & \multirow[t]{2}{*}{$\begin{array}{c}P \\
\text { value }\end{array}$} \\
\hline & & & & & \\
\hline Age & 64 & $58-72$ & 67 & $58-74$ & .1405 \\
\hline Sex (woman) & 36 & $34.6 \%$ & 68 & $27.4 \%$ & .1581 \\
\hline Operative status & & & & & .7435 \\
\hline Elective & 72 & $69.2 \%$ & 234 & $70.9 \%$ & \\
\hline Urgent & 32 & $30.8 \%$ & 96 & $29.1 \%$ & \\
\hline Winnipeg residence & 51 & $49.0 \%$ & 183 & $55.5 \%$ & .2524 \\
\hline $\begin{array}{r}\text { Preoperative ejection } \\
\text { fraction severity }\end{array}$ & & & & & .0216 \\
\hline$\geq 50$ & 61 & $65.6 \%$ & 245 & $78.5 \%$ & \\
\hline$\leq 30$ to $<50$ & 23 & $24.7 \%$ & 54 & $17.3 \%$ & \\
\hline$<30$ & 9 & $9.7 \%$ & 13 & $4.2 \%$ & \\
\hline $\begin{array}{l}\text { CCS class } \\
\text { (III or IV) }\end{array}$ & 62 & $59.6 \%$ & 174 & $52.4 \%$ & .1981 \\
\hline $\begin{array}{r}\text { NYHA class } \\
\text { (III or IV) }\end{array}$ & 33 & $31.7 \%$ & 68 & $20.5 \%$ & .0177 \\
\hline $\begin{array}{r}\text { Preoperative } \\
\text { creatinine }\end{array}$ & 75.5 & $62-93.5$ & 76.5 & $64.5-92$ & .5075 \\
\hline Smoker & 27 & $26.2 \%$ & 86 & $26.2 \%$ & .9990 \\
\hline Dyslipidemia & 77 & $74.0 \%$ & 257 & $77.6 \%$ & .4475 \\
\hline Hypertension & 85 & $81.7 \%$ & 251 & $75.8 \%$ & .2106 \\
\hline Diabetes mellitus & 36 & $34.6 \%$ & 106 & $32.0 \%$ & .6230 \\
\hline $\begin{array}{l}\text { Peripheral vascular } \\
\text { disease }\end{array}$ & 16 & $15.5 \%$ & 39 & $11.9 \%$ & .3336 \\
\hline CVA or TIA & 13 & $12.8 \%$ & 40 & $12.2 \%$ & .8747 \\
\hline$\geq 2$ Risk factors* & 83 & $81.4 \%$ & 248 & $75.8 \%$ & .2453 \\
\hline$\geq 3$ Risk factors* & 52 & $51.0 \%$ & 163 & $49.9 \%$ & .8416 \\
\hline$\geq 4$ Risk factors* & 21 & $20.6 \%$ & 66 & $20.2 \%$ & .9293 \\
\hline Physical activity & & & & & .0010 \\
\hline Inactive & 51 & $49.5 \%$ & 105 & $31.7 \%$ & \\
\hline Active $\dagger$ & 52 & $50.5 \%$ & 226 & $68.3 \%$ & \\
\hline IPAQ minutes & 664.5 & $65.5-2617$ & 1188 & $347-3672$ & .0111 \\
\hline $\begin{array}{c}\text { Time spent on } \\
\text { waitlist (d) }\end{array}$ & 46.5 & $19-96$ & 57 & $26-110$ & .2371 \\
\hline \multicolumn{6}{|l|}{ Operative } \\
\hline Procedure & & & & & .5640 \\
\hline Isolated CABG & 63 & $60.6 \%$ & 185 & $55.7 \%$ & \\
\hline Isolated valve & 19 & $18.3 \%$ & 54 & $16.3 \%$ & \\
\hline $\mathrm{CABG}+$ valve & 7 & $6.7 \%$ & 26 & $7.8 \%$ & \\
\hline Other & 15 & $14.4 \%$ & 67 & $20.2 \%$ & \\
\hline $\begin{array}{c}\text { All CABG procedures } \\
(\mathrm{C}+\mathrm{V} \text { or ISO } \mathrm{C})\end{array}$ & 70 & $67.3 \%$ & 211 & $63.6 \%$ & .4853 \\
\hline
\end{tabular}

CCS, Canadian Cardiovascular Society; NYHA, New York Heart Association; CVA, cerebro-vascular accident; TIA, transient ischemic attack; IPAQ, International Physical Activity Questionnaire; $C A B G$, coronary artery bypass grafting; $C+\operatorname{Vor} I S O C$, $\mathrm{CABG}$ plus valve procedure or isolated $\mathrm{CABG}$. *Risk factors included coronary artery risk factors of chronic renal insufficiency (creatinine $\geq 110 \mu \mathrm{mol} / \mathrm{L}$ ), hyperlipidemia, hypertension, smoking, diabetes, peripheral vascular disease, and CVA/TIA. $\dagger$ Physically active refers to patients identified as moderately and very physically active preoperatively.

that overwhelms the already taxed coping resources of many patients and precipitates or exacerbates depressive symptomatology. ${ }^{11}$ 
TABLE 2. Summary of preoperative (only significant parameters), operative, and postoperative variables comparing depressed patients (includes newly depressed patients previously naïve or at risk, plus previously depressed patients who remained depressed) with patients not depressed at discharge from hospital

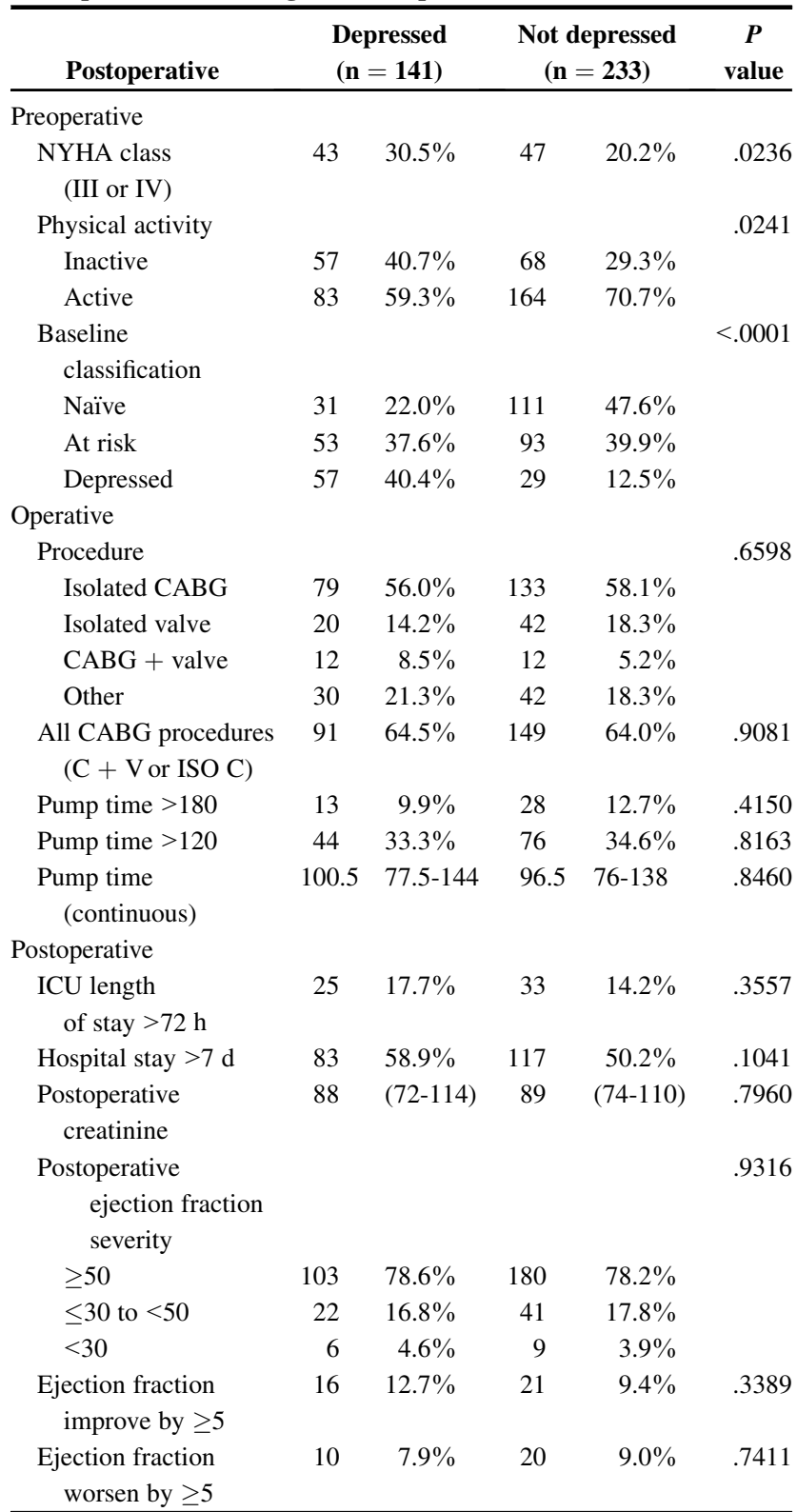

NYHA, New York Heart Association; $C A B G$, coronary artery bypass grafting; $C+V$ or ISO $C$, CABG plus valve procedure or isolated CABG; $I C U$, intensive care unit.

\section{Heterogeneity of Depressive Symptoms in Different Subgroups}

Approximately $30 \%$ of patients had PHQ-9 scores consistent with depression, thus highlighting depression as a common postprocedural problem..$^{3-6,12}$ Rudisch and colleagues ${ }^{13}$ reported a $17 \%$ to $27 \%$ prevalence of depression in nonoperative cardiovascular patients, which is in keeping with our observed prevalence of preoperative
TABLE 3. Depression scoring classification

\begin{tabular}{lccll}
\hline $\begin{array}{c}\text { PHQ-9 } \\
\text { score }\end{array}$ & $\begin{array}{c}\text { No. of responses } \\
\text { on PHQ-9 }\end{array}$ & $\begin{array}{c}\text { Risk } \\
\text { factors* }\end{array}$ & $\begin{array}{c}\text { Degree of } \\
\text { depression }\end{array}$ & $\begin{array}{c}\text { Baseline } \\
\text { classification }\end{array}$ \\
\hline $0-4$ & Any & No & Not & Naive \\
$0-4$ & Any & Yes & Not & At risk \\
$5-9$ & $<3$ & n/a & Possibly & At risk \\
$5-9$ & $>3$ & n/a & Mild & Depressed \\
$10-14$ & Any & n/a & Mild & Depressed \\
$15-20$ & Any & n/a & Moderate & Depressed \\
$20-27$ & Any & n/a & Severe & Depressed \\
\hline
\end{tabular}

PHQ-9, Patient Hospital Questionnaire-9; $n / a$, not applicable. *Risk factors included family history of depression, previous diagnosis of depression, currently controlled using antidepressants, living alone, and recent stressful event.

depression of $23.9 \%$. The overall increased prevalence of any depression at discharge $(37.7 \%)$ observed in this study appears to be in contrast to improvement in symptoms noted in a review by McKenzie and colleagues. ${ }^{12}$ Murphy and colleagues ${ }^{14}$ indicated there are subgroups of patients who show marked heterogeneity in depressive symptoms over time with some showing no improvement or worsening of their symptoms following surgery. Indeed, we identified 2 patterns of depressed mood after cardiac surgery. The preoperative depressed patients had a generalized improvement in depression, whereas an increase in depression, primarily in at-risk patients, was observed. This stresses the importance of identifying these subgroups because this potentially carries implications for psychological interventions as well as the long-term medical outcomes for these groups.

The incidence of new depression (29\%) from the at-risk and naïve subgroups ( $58 \%$ vs $28 \%$, respectively) highlights how even minor levels of depressive symptoms, or having risk factors for depression, can accentuate individuals' reactions to acute stressors. These individuals could be viewed as being more physically and emotionally vulnerable to the stresses of the surgical intervention than the cohort who did not become depressed. Moreover, it is a possibility that they were faced with the additional stress of a prolonged and probably more complicated inpatient admission (ie, greater length of stay) that further taxed their coping skills. This supports the practice of psychological screening of cardiac patients for

TABLE 4. Physical activity scoring classification

\begin{tabular}{lll}
\hline $\begin{array}{c}\text { MET min/wk } \\
\text { score* }\end{array}$ & $\begin{array}{c}\text { IPAQ categorical } \\
\text { score }\end{array}$ & $\begin{array}{c}\text { IPAD-CS } \\
\text { classification }\end{array}$ \\
\hline$<600$ & Inactive & Inactive \\
$>600$ & Moderately active & Active \\
$>1500$ of vigorous activity & Physically active & Active \\
$>3000$ of any activity & Physically active & Active \\
\hline
\end{tabular}

$M E T$, Metabolic equivalent of task; IPAQ, International Physical Activity Questionnaire; IPAD-CS, Impact of Physical Activity on Depression after Cardiac Surgery Study. *MET minutes per week were calculated for each patient (MET level $\times$ minutes of activity $\times$ events per week). Each category of activity was assigned a MET level (vigorous activity $=8$ METs, moderate activity $=4$ METs, and walking activity $=3.3$ METs). 
TABLE 5. Summary of independent preoperative (Q1) and postoperative $(\mathrm{Q} 2)$ variables placing patients at risk of developing depression, after multivariate logistic regression

\begin{tabular}{|c|c|c|c|}
\hline $\begin{array}{l}\text { Multivariable logistic } \\
\text { model risk factor }\end{array}$ & $\begin{array}{l}\text { Odds } \\
\text { ratio }\end{array}$ & $\begin{array}{l}95 \% \text { Confidence } \\
\text { interval }\end{array}$ & $\begin{array}{c}P \\
\text { value }\end{array}$ \\
\hline \multicolumn{4}{|l|}{ Q1: Depression } \\
\hline $\begin{array}{l}\text { Moderate preoperative ejection } \\
\text { fraction } \leq 30 \text { to }<50\end{array}$ & 1.81 & $(1.02-3.21)$ & .041 \\
\hline $\begin{array}{l}\text { Severe preoperative ejection } \\
\text { fraction }(<30)\end{array}$ & 2.81 & $(1.13-6.96)$ & .0261 \\
\hline Physically inactive & 2.05 & $(1.30-3.23)$ & .0019 \\
\hline \multicolumn{4}{|l|}{ Q2: Depression } \\
\hline At-risk group (baseline) & 2.16 & $(1.28-3.67)$ & .0042 \\
\hline Depressed group (baseline) & 7.46 & $(4.06-13.69)$ & $<.0001$ \\
\hline Hospital stay $>7 \mathrm{~d}$ & 1.62 & $(1.03-2.55)$ & .0387 \\
\hline \multicolumn{4}{|l|}{$\begin{array}{l}\text { Q2: New depression (at risk and } \\
\text { naïve patients only) }\end{array}$} \\
\hline NYHA class III or IV & 2.06 & $(1.1-3.81)$ & .0212 \\
\hline At-risk group & 2.02 & $(1.17-3.48)$ & .0119 \\
\hline Hospital stay $>7 \mathrm{~d}$ & 2.16 & $(1.25-3.75)$ & .0039 \\
\hline \multicolumn{4}{|l|}{$\begin{array}{l}\text { Q2: Remained depressed } \\
\quad \text { (depressed at Q1 patients only) }\end{array}$} \\
\hline CCS class III or IV & 4.22 & $(1.47-12.08)$ & .0073 \\
\hline $\begin{array}{l}\text { Severe preoperative ejection } \\
\text { fraction }(<30)\end{array}$ & 10.53 & $(1.72-66.67)$ & .0110 \\
\hline
\end{tabular}

NYHA, New York Heart Association; CCS, Canadian Cardiovascular Society.

depressive risk factors and negative emotions at several points during the pre- and postoperative recovery period.

One-third of preoperatively depressed patients were found to have normal mood at discharge, highlighting another different pattern of depression in cardiac surgery patients. Notably an improvement in the median PHQ-9 score for the depressed subgroup postoperatively was observed. A possible explanation for the remission of depression in some of the depressed patients is the link between depression and ruminative and catastrophic thinking. ${ }^{15}$ These thought processes could have heightened depressive symptoms before surgery due to the uncertainty

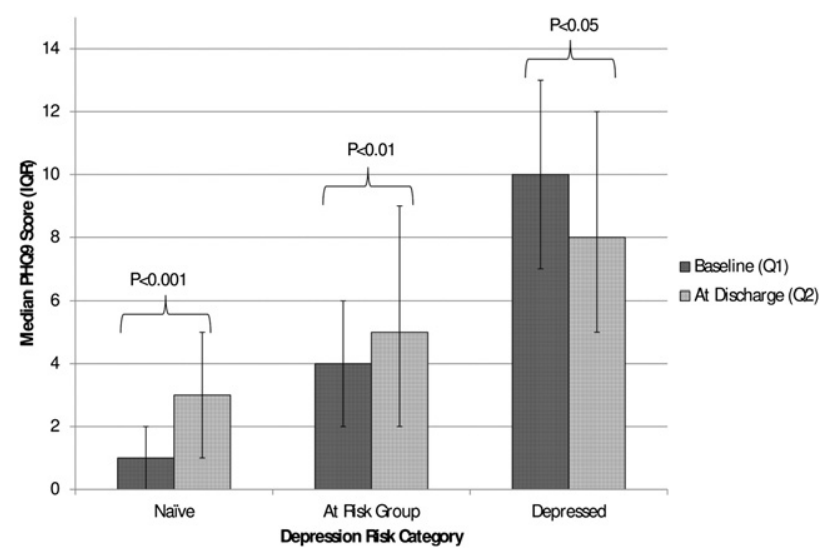

FIGURE 2. Median Patient Health Questionnaire-9 (PHQ-9) scores by depression category. $I Q R$, Interquartile range.

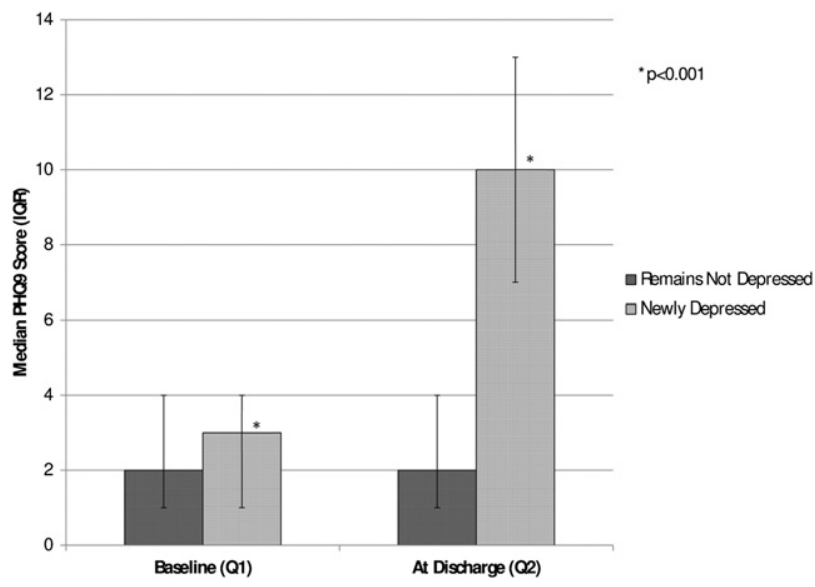

FIGURE 3. Median Patient Health Questionnaire-9 (PHQ-9) scores of patients without depression. $I Q R$, Interquartile range. ${ }^{*} P<.001$.

surrounding outcomes (ie, survival vs death). ${ }^{15}$ They would become less relevant following an immediate positive surgical outcome and hence accompanied by a decrease in depressive mood and negative processes. McKann and colleagues ${ }^{6}$ reported a similar finding in that about half of the patients in their study who were depressed before surgery were no longer depressed at 1-month follow-up. They speculated that improvement in physical functioning seen in many patients following CABG may have the added effect of elevating mood. Sansone and colleagues ${ }^{15}$ believed that the greater amounts of pain experienced by the unremitted depressed patients provided constant fuel for their negative expectations being realized and consequently the persistence of their depression. ${ }^{15}$

\section{Influence of Physical Activity}

Pre- and postoperative Cognitive Behavior Therapy (including exercise components) are beginning to show

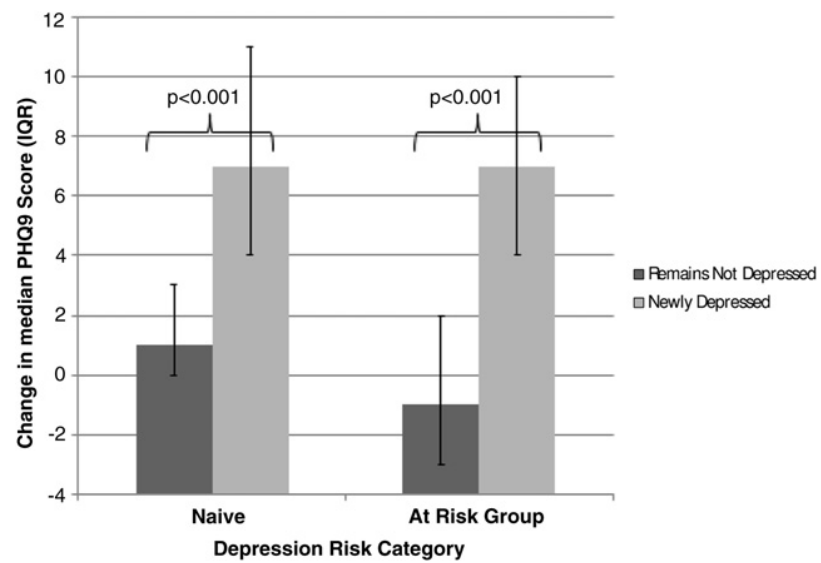

FIGURE 4. Change in median Patient Health Questionnaire-9 (PHQ-9) scores of patients without depression (discharge - baseline score). IQR, Interquartile range. 
some promise in treating anxiety and depression in patients undergoing cardiac surgery. ${ }^{16}$ These are best implemented early following their surgery to allow for a normative adjustment reaction to take place. ${ }^{17}$ The relationship between physical activity and depressive symptoms are not fully understood. There is a growing body of evidence indicating a beneficial association between physical activity and depression amongst people with cardiovascular disease. ${ }^{18}$ Whether withdrawal from physical activity leads to depressive $^{19}$ symptoms or if depression leads to a sedentary lifestyle $^{20}$ still remains to be elucidated. To our knowledge, this is the first study to provide evidence indicating an association between preoperative self-reported cardiac surgery patient physical activity levels and depressive symptoms perioperatively.

\section{Limitations}

One of the limitations in our study is that being categorized as depressed by the PHQ-9 does not imply having a major depressive disorder as this can only be diagnosed with a clinical interview using Diagnostic and Statistical Manual of Mental Disorders, Fourth Edition ${ }^{9}$ criteria. The PHQ-9 has been shown to be an effective depression screening tool for cardiac populations ${ }^{7,21-23}$ with good psychometric properties and clinical utility. ${ }^{8,24}$ In addition, discrete cutoff scores for caseness $^{7,22,23}$ (numerical value on a test indicator at or above which a respondent is considered to be a positive case) have been ascertained that show good sensitivity $(81.5 \%)$, specificity $(80.6 \%)$, positive predictive value $(62 \%)$, and negative predictive value $(91.8 \%)$ for any depressive disorder. ${ }^{22}$ In addition, some of the symptoms of depression overlap with anxiety or acute stress reactions (both of which are evident after cardiac surgery), and somatic symptoms like lack of energy, sleep disturbances, loss of appetite, and moving slowly are commonly seen immediately after cardiac surgery. In lieu of this potential overlap, an adjustment to the mild category (PHQ-9 score 5-14) of depression to also include a possibly depressed category (PHQ-9 score 5-9) was made to minimize a high false positive identification of mild depression. ${ }^{7}$ Possibly depressed patients that answered positive to more than 3 different questions (thus meet the criteria for minor depressive episode according to the Diagnostic and Statistical Manual of Mental Disorders, Fourth Edition ${ }^{9}$ criteria), were changed to being mildly depressed. Because interviewing patients identified to be depressed was outside the scope of this project, sensitivity and specificity of the PHQ-9 in our population could not be confirmed. Unlike other depression screening tools, the PHQ-9 is a free questionnaire that does not add additional cost as a screening tool to cardiac surgery programs.

A further limitation is the high likelihood of over selfreporting physical activity with the short form IPAQ. ${ }^{25}$ Patients in our study reported accumulating on average 224 minutes (3.7 hours) of moderate to vigorous physical activity weekly at their baseline assessment preoperatively (Q1). This is well above the recommended weekly 150 minutes of moderate to vigorous physical activity for optimal health. Even so, these data are consistent with previous literature indicating that people tend to over-report their physical activity when using self-reporting methods. ${ }^{10,25}$ The IPAQ has been shown though, to have a correlation of $\rho=0.3$ with objective measures of physical activity (ie, accelerometry). ${ }^{10}$

Thirdly, the absence of testing for postoperative anxiety and neurocognitive dysfunction is another limitation because patients with an acute stress response could experience a mixture of depressive and anxiety symptoms postoperatively. Our intention was to evaluate depression as a single entity and not postoperative stress responses. McKann and colleagues ${ }^{6}$ found no relation between depression and neurocognitive disorders.

A total of 62 patients enrolled did not complete the questionnaires at discharge (Figure 1); however, there was no difference in results when analysis was performed with only patients who completed Q1 and Q2, compared with analysis including all 436 Q1 and 374 Q2 questionnaires.

\section{CONCLUSIONS}

Depression is prevalent in approximately one-third of patients undergoing cardiac surgery at the time of discharge. Preoperatively depressed patients tend to have an improvement in depression scores, whereas other patients have worsening of depressive symptoms. Our study demonstrates that depression following cardiac surgery is not associated with any operative or postoperative risk factors with the exception of prolonged hospital stay $>7$ days. Preoperative depression or being at risk for depression adds a 7-fold and 2-fold risk for postoperative depression, respectively. Preoperative physical inactivity independently adds a 2-fold risk for preoperative depression. Questions remaining, such as how many of these patients remain depressed, how physical activity influences depression postoperatively, and the influence of depression and physical activity on medium or long-term morbidity and mortality after cardiac surgery remain to be answered in the follow-up reporting from the Impact of Physical Activity on Depression after Cardiac Surgery study. Future studies are necessary to develop effective, timely treatment strategies for the different subgroups of depressed patients before and after cardiac surgery.

\section{References}

1. Connerney I, Shapiro PA, McLaughlin JS, Bagiella E, Sloan RP. Relation between depression after coronary artery bypass surgery and 12-month outcome a prospective study. Lancet. 2001;358:1766-71.

2. Tully PJ, Pedersen SS, Winefield HR, Baker RA, Turnbull DA, Denollet J. Cardiac morbidity risk and depression and anxiety: a disorder, symptom and trait analysis among cardiac surgery patients. Psychol Health Med. 2011;16:333-45.

3. Tully PJ, Baker RA. Depression, anxiety, and cardiac morbidity outcomes after coronary artery bypass surgery: a contemporary and practical review. J Geriat Cardiol. 2012;9:197-208. 
4. Tully PJ, Baker RA, Turnbull D, Winefield H. The role of depression and anxiety symptoms in hospital readmissions after cardiac surgery. J Behav Med. 2008;31: 281-90.

5. Blumenthal JA, Lett HS, Babyak MA, White W, Smith PK, Mark DB, et al. Depression as a risk factor for mortality after coronary artery bypass surgery. Lancet. 2003;362:604-9.

6. McKann GM, Borowicz LM, Goldsborough MA, Enger C, Selnes OA. Depression and cognitive decline after coronary artery bypass grafting. Lancet. 1997; 349:1282-4.

7. Lichtman JH, Bigger JT Jr, Blumenthal JA, Frasure-Smith N, Kaufmann PG, Lespérance $\mathrm{F}$, et al. Depression and coronary heart disease: recommendations for screening, referral, and treatment. A science advisory from the American Heart Association Prevention Committee. Circulation. 2008;118:1768-75.

8. Kroenke K, Spitzer RL, Williams JB. The PHQ-9: validity of a brief depression severity measure. J Gen Intern Med. 2001;16:606-13.

9. American Psychiatric Association. Diagnostic and statistical manual of mental disorders. 4th ed. Washington, DC: American Psychiatric Association; 2000.

10. Craig CL, Marshall AL, Sjostrom M, Bauman AE, Booth ML, Ainsworth BE, et al. International physical activity questionnaire: 12-country reliability and validity. Med Sci Sports Exerc. 2003;35:1381-95.

11. Luttik ML, Jaarsma T, Sanderman R, Fleer J. The advisory brought to practice: routine screening on depression (and anxiety) in coronary heart disease; consequences and implications. Eur J Cardiovasc Nurs. 2011;10:228-33.

12. McKenzie LH, Simpson J, Stewart M. A systematic review of pre-operative predictors of post-operative depression and anxiety in individuals who have undergone coronary artery bypass graft surgery. Psychol Health Med. 2010;15:74-93.

13. Rudisch B, Nemeroff CB. Epidemiology of comorbid coronary artery disease and depression. Biol Psychiatr. 2003;54:227-40.

14. Murphy BM, Elliot PC, Higgins MR, Le Grande MR, Worcester MU, Goble AJ, et al. Anxiety and depression after coronary bypass surgery: most get better, some get worse. Eur J Cardiovasc Prev Rehabil. 2008;15:434-40.
15. Sansone RA, Sansone LA. Rumination: relationships with physical health. Innov Clin Sci. 2012;9:29-34.

16. Rosenfeldt F, Braun L, Spitzer O, Bradley S, Shepherd J, Bailey M, et al. Physical conditioning and mental stress reduction - a randomized trial in patients undergoing cardiac surgery. BMC Complement Altern Med. 2011;11:20.

17. Doering LV, Chen B, Cross Bodán R, Magsarili MC, Nyamathi A, Irwin MR. Early Cognitive Behavioral Therapy for depression after cardiac surgery. J Cardiovasc Nurs. 2012 May 24 [Epub ahead of print].

18. Win S, Parakh K, Eze-Nliam CM, Gottdiener JS, Kop WJ, Ziegelstein RC. Depressive symptoms, physical inactivity and risk of cardiovascular mortality in older adults: the Cardiovascular Health Study. Heart. 2011;97:500-5.

19. Berlin AA, Kop WJ, Deuster PA. Depressive mood symptoms and fatigue after exercise withdrawal: the potential role of decreased fitness. Psychosom Med. 2006;68:224-30.

20. Roshanaei-Moghaddam B, Katon WJ, Russo J. The longitudinal effects of depression on physical activity. Gen Hosp Psychiatry. 2009;31:306-15.

21. McManus D, Pipkin SS, Whooley MA. Screening for depression in patients with coronary heart disease: data from the Heart and Soul study. Am J Cardiol. 2005; 96:1076-81.

22. Stafford L, Berk M, Jackson HJ. Validity of the Hospital Anxiety and Depression Scale and the Patient Health Questionnaire-9 to screen for depression in patients with coronary artery disease. Gen Hosp Psychiatr. 2007;29:417-24.

23. Ketterer MW, Brawner CA, Van Zant M, Keteyian S, Ehrman JK, Knysz W, et al. Empirically derived psychometric screening for emotional distress in coronary artery disease patients. J Cardiovasc Nurs. 2007;22:320-5.

24. Wittkampf KA, Naeije L, Schene AH, Huyser J, van Weert HC. Diagnostic accuracy of the mood module of the Patient Health Questionnaire: a systematic review. 2007. Gen Hosp Psychiatr. 2007;29:388-95.

25. Lee PH, Macfarlane DJ, Lam TH, Stewart SM. Validity of the International Physical Activity Questionnaire Short Form (IPAQ-SF): a systematic review. Int J Nutr Phys Act. 2011;8:115. 